\title{
Who's responsible for the care of women during and after a pregnancy affected by gestational diabetes?
}

\section{Shelley A Wilkinson BSc(Hons), GradDipNut\&Diet, Senior Maternity Research Dietitian, and Chief Investigator $^{2}$ \\ Siew S Lim BSc, MND, PhD Postdoctoral Research Fellow ${ }^{2,3}$ \\ Susan Upham BSocWk, GradDipHealthPromotion, \\ Research Assistant ${ }^{2}$}

Andrew Pennington BSc(Hons), BMed, FRACGP General Practitioner and Honorary Fellow ${ }^{4}$

Sharleen L O'Reilly $\mathrm{BSc}$ (Hons), $\mathrm{PhD}$ NHMRC TRIP Fellow ${ }^{5}$

Dino Asproloupos NHMRC Senior Program Manager $^{3}$

\section{H David Mclntyre}

Head, ${ }^{6}$ and Head of Theme $^{7}$

James A Dunbar MD, FRCPEdin, FRCGP Director ${ }^{3}$

1 Nutrition and Dietetics, Mater Research, Brisbane, QLD.

$\mathbf{2}$ Centre of Research

Excellence in Primary Health Care Microsystems, University of Queensland, Brisbane, QLD.

3 Greater Green Triangle University Department of Rural Health, Flinders and Deakin Universities, Warrnambool, VIC.

4 Department of General Practice, University of Melbourne, Melbourne, VIC.

5 Centre for Physical Activity and Nutrition Science, Deakin University, Melbourne, VIC.

6 Mater Clinical School, University of Queensland and Mater Medical Research Institute, Brisbane, QLD.

7 Mothers' and Babies' Health, Mater Research Institute, Brisbane, QLD.

shelley.wilkinson@ mater.org.au

doi: 10.5694/mjal4.00251

Online first 21/07/14

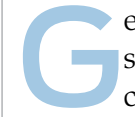
estational diabetes mellitus (GDM) is the strongest single population predictor of type 2 diabetes, ${ }^{1}$ and current Australian prevalence is 10\%-13\%, depending on the criteria used. ${ }^{2}$ Poor health outcomes extend to children of mothers who had GDM, due to increased risk of obesity and abnormal glucose metabolism during childhood, adolescence and adulthood. ${ }^{3}$

Antenatal lifestyle intervention is shown to improve short- and long-term maternal and infant health outcomes. ${ }^{3}$ In addition, it can effectively prevent type 2 diabetes among women who have had GDM. ${ }^{1}$ However, although some centres of excellence exist, in many cases, antenatal care is not delivered systematically. ${ }^{4}$

After their babies are born, women who have had GDM can be described as falling into a health care "chasm". ${ }^{5}$ When these women leave hospital, their obstetricians and endocrinologists feel that their work is done. Lack of coordination between the hospital and primary care sectors can mean that no one assumes responsibility for the care of these women.

The opportunity to prevent or delay type 2 diabetes in this high-risk population through primary care was noted more than a decade ago. ${ }^{6}$ However, defined care pathways and coordination remain elusive; implementation of evidence has not occurred. In many cases, general practitioners may not be aware that the woman has had GDM, and may not have a clear pathway directing responsibility for follow-up care.

There is an urgent need to implement a widespread and coordinated approach to prevent progression to type 2 diabetes in this population. Rectifying this situation requires cooperation and collaboration between all care providers.

\section{Antenatal care: navigating the new gestational diabetes landscape}

The health care sector operates under guidelines with conflicting content and differing levels of comprehensiveness and professional endorsement (Box). The Australasian Diabetes in Pregnancy Society (ADIPS) recently released revised consensus guidelines for testing and diagnosing GDM in Australia and New Zealand.7

Women with GDM are managed in hospitals because they are identified as having pregnancies at higher risk of adverse outcomes. The ADIPS guidelines recommend an oral glucose tolerance test (OGTT) for all women (unless already diagnosed with GDM in early pregnancy) at 24-28 weeks' gestation. ${ }^{7}$ These guidelines were informed by several studies, including the Hyperglycemia and Adverse Pregnancy Outcome (HAPO) Study, which indicated a strong continuous association of maternal glucose levels with increased diabetic fetopathy. ${ }^{14}$

A change to testing protocols will be introduced in July 2014 and diagnostic criteria on 1 January 2015 (Aidan

\section{Summary \\ Despite its increasing incidence and high conferred risk to women and their children, gestational diabetes mellitus (GDM) is managed inconsistently during and after pregnancy due to an absence of a systemic approach to managing these women. \\ New guidelines for GDM testing and diagnosis are based on stronger evidence, but raise concerns about increased workloads and confusion in a landscape of multiple, conflicting guidelines. \\ Postnatal care and long-term preventive measures are particularly fragmented, with no professional group taking responsibility for this crucial role. \\ Clearer guidelines and assistance from existing frameworks, such as the National Gestational Diabetes Register, could enable general practitioners to take ownership of the management of women at risk of type 2 diabetes following GDM, applying the principles of chronic disease management long term.}

McElduff, Clinical Associate Professor of Medicine, University of Sydney and ADIPS President; personal communication). Concerns exist about their potential workload implications and evidence base.

Health service and pathology database analyses have resulted in equivocal projections of the potential workload increases; it is most likely that many will see a doubling of cases. ${ }^{2,15}$ Workload projections can be difficult, as true prevalence is not known, but it has been suggested that the increasing rate reflects the prevalence of abnormal glucose metabolism in the general population. ${ }^{16}$

In considering potential workload costs and changes, we need to consider the results from two well executed randomised controlled trials, which demonstrated that treatment of GDM can prevent adverse outcomes. ${ }^{17,18}$ For most women ( $80 \%-90 \%)$, GDM could be managed through dietary counselling delivered by a dietitian. In some centres, this proportion will be lower, depending on population characteristics. Medical nutrition therapy is a cornerstone intervention for women with GDM, ${ }^{19}$ and its appropriate delivery results in reduced insulin requirements and improved blood glucose control. ${ }^{19}$ However, systematic, evidence-based dietetic care of women with GDM does not occur in many centres in Australia. ${ }^{4}$ Australian health services require clinician leadership and commitment to partnership and change in (re)allocation of resources to support a multidisciplinary team in providing evidencebased care for improved maternal and infant outcomes.

Some clinicians raise concerns about diagnostic criteria changes based on observational study outcomes, but the previous diagnostic criteria were the product of an ad-hoc working party and lacked the strong evidence base that underpins the current criteria. ${ }^{20}$ 
Postnatal follow-up: who's taking responsibility?

Australian guidelines recommend that all women who had GDM should undertake a $75 \mathrm{~g}$ OGTT between 6 and 12 weeks after delivery. ${ }^{7}$ International guidelines also highlight the importance of lifestyle modification, breastfeeding, birth control and risk counselling to improve health outcomes for these women and their children.12,13

The extent to which these recommendations are integrated into postnatal GP visits is not known, but some studies suggest diabetes testing is suboptimal. ${ }^{21}$ Self-report surveys of women with prior GDM indicated that about half of participants returned for OGTTs, but only a quarter in the appropriate period..$^{21,22}$ The potential use of glycated haemoglobin testing instead of the OGTT appeals to many, but the approach may not change until it is approved on the Medicare Benefits Schedule.

Appropriate strategies to engage women in screening are paramount, as the motivation to manage a GDM diagnosis transforms to apathy once GDM resolves. ${ }^{23}$ Barriers to ongoing screening include a lack of awareness of the need for screening, difficulty attending screening with an infant, dislike of the OGTT process, being a mobile population, and inconsistent advice from health care providers about testing, lifestyle modification and risk. ${ }^{21-23}$ Findings from the United Kingdom suggest that health care professionals need to balance between reassurance of likely resolution of GDM and adequate information about potential progression to type 2 diabetes. ${ }^{23}$ Perception of risk is an important motivator; a lack of perceived risk of developing type 2 diabetes is common and can be related to timing, content and tone of messages. ${ }^{23,24}$

\section{Prevention of diabetes in primary care}

\section{Which guidelines?}

Three Australian guidelines exist for the follow-up of women who are at risk of type 2 diabetes (Box). ${ }^{7-9}$ Their core messages are similar, but they vary in several areas, diluting GP awareness and implementation. Beyond the timing of

\section{A comparison of current gestational diabetes mellitus diagnosis (GDM), treatment and follow-up guidelines}

\section{Details of guidelines}

\begin{tabular}{|c|c|c|c|c|c|c|c|}
\hline $\begin{array}{l}\text { Guideline/society } \\
\text { (country) }\end{array}$ & $\begin{array}{l}\text { ADIPS (Australia and } \\
\text { New Zealand) }{ }^{7}\end{array}$ & $\begin{array}{l}\text { Diabetes Australia } \\
\text { and RACGP } \\
\text { (Australia) }^{8}\end{array}$ & $\begin{array}{l}\text { Therapeutic } \\
\text { guidelines: } \\
\text { endocrinology } \\
\text { (Australia) }\end{array}$ & ACOG $(\text { US })^{10}$ & ADA (US)" & NICE $(\text { UK })^{12}$ & CDA (Canada) $)^{13}$ \\
\hline $\begin{array}{l}\text { Antenatal testing } \\
\text { protocol }\end{array}$ & $\begin{array}{l}\text { Universal OGTT at } 24-28 \\
\text { weeks; earlier if clinically } \\
\text { indicated }\end{array}$ & $\begin{array}{l}\text { Universal screening } \\
\text { at } 26-28 \text { weeks. } \\
\text { Two-step approach } \\
\text { recommended } \\
\text { (GCT then OGTT). }\end{array}$ & $\begin{array}{l}\text { Universal GCT or } \\
\text { OGTT at } 26 \text { weeks. } \\
\text { Early screening if } \\
\text { high risk }\end{array}$ & - & $\begin{array}{c}\text { Universal } \\
\text { OGTT at } \\
\text { 24-28 weeks } \\
\text { in women not } \\
\text { previously } \\
\text { diagnosed with } \\
\text { overt diabetes }\end{array}$ & $\begin{array}{l}\text { At } 24-28 \\
\text { weeks if } \\
\text { the woman } \\
\text { has any risk } \\
\text { factors or } \\
\text { earlier if GDM } \\
\text { in a previous } \\
\text { pregnancy }\end{array}$ & $\begin{array}{l}\text { Universal screening } \\
\text { 24-28 weeks. Two-step } \\
\text { approach preferred } \\
\text { (GCT then OGTT) }\end{array}$ \\
\hline $\begin{array}{l}\text { Timing of first } \\
\text { postpartum } \\
\text { follow-up visit }\end{array}$ & 6-12 weeks & $6-12$ weeks & $6-12$ weeks & $6-12$ weeks & 6-12 weeks & 6 weeks & 6 weeks -6 months \\
\hline $\begin{array}{l}\text { Which test(s) } \\
\text { for postpartum } \\
\text { screening }\end{array}$ & 75 g OGTT & 75 g OGTT & 75 g OGTT & $\begin{array}{l}\text { FPG or } 75 \mathrm{~g} \\
\text { OGTT }\end{array}$ & $\begin{array}{c}75 \text { g OGTT; not } \\
\mathrm{HbA}_{\mathrm{lc}}\end{array}$ & FPG & 75 g OGTT \\
\hline Who with? & - & GP & - & - & - & - & - \\
\hline $\begin{array}{l}\text { Frequency of } \\
\text { follow-up and } \\
\text { recommended test }\end{array}$ & $\begin{array}{l}\text { Dependent on future } \\
\text { pregnancy plans and } \\
\text { perceived risk of type } 2 \\
\text { diabetes, yearly OGTT if } \\
\text { planning pregnancy. 1-2 } \\
\text { yearly FPG (low risk); } \\
\text { OGTT/HbA }_{\mathrm{lc}} \text { (higher risk) }\end{array}$ & 3-yearly; with FPG & $\begin{array}{l}\text { If postnatal test } \\
\text { normal: annual } \\
\text { fasting or random } \\
\text { blood glucose } \\
\text { or OGTT every } 2 \\
\text { years and before } \\
\text { subsequent } \\
\text { planned } \\
\text { pregnancies }\end{array}$ & $\begin{array}{l}\text { 3-yearly, as } \\
\text { above }\end{array}$ & $\begin{array}{l}\text { Minimum } \\
\text { 3-yearly; with } \\
\text { OGTT. If IFG or } \\
\text { IGT, yearly }\end{array}$ & $\begin{array}{l}\text { Yearly; no } \\
\text { blood test } \\
\text { specified }\end{array}$ & $\begin{array}{l}\text { At least 3-yearly and } \\
\text { before each pregnancy; } \\
\text { not specified }\end{array}$ \\
\hline $\begin{array}{l}\text { Other postnatal } \\
\text { advice included }\end{array}$ & No recommendations & $\begin{array}{l}\text { Increase physical } \\
\text { activity, weight } \\
\text { loss/healthy diet. } \\
\text { Refer to dietitian } \\
\text { and/or physical } \\
\text { activity program. } \\
\text { Preconception } \\
\text { advice. }\end{array}$ & $\begin{array}{l}\text { Risk counselling } \\
\text { for future type } 2 \\
\text { diabetes. Lifestyle } \\
\text { advice: diet/ } \\
\text { physical activity. } \\
\text { Subsequent } \\
\text { pregnancy: early } \\
\text { screening } 12-16 \\
\text { weeks repeated at } \\
26 \text { weeks. }\end{array}$ & $\begin{array}{l}\text { Weight loss } \\
\text { and physical } \\
\text { activity } \\
\text { counselling as } \\
\text { needed }\end{array}$ & $\begin{array}{l}\text { Women with } \\
\text { a history of } \\
\text { gestational } \\
\text { diabetes } \\
\text { found to have } \\
\text { prediabetes } \\
\text { should receive } \\
\text { lifestyle } \\
\text { interventions } \\
\text { or metformin } \\
\text { to prevent } \\
\text { diabetes. }\end{array}$ & $\begin{array}{l}\text { Lifestyle } \\
\text { advice: } \\
\text { weight } \\
\text { control, diet } \\
\text { and exercise }\end{array}$ & $\begin{array}{l}\text { Lifestyle advice to } \\
\text { prevent diabetes } \\
\text { and cardiovascular } \\
\text { disease should begin } \\
\text { in pregnancy and } \\
\text { continue postpartum. } \\
\text { Encourage breastfeeding } \\
\text { for at least } 3 \text { months } \\
\text { postpartum. Provide } \\
\text { risk and preconception } \\
\text { counselling. }\end{array}$ \\
\hline
\end{tabular}

ACOG = American College of Obstetricians and Gynecologists. ADA = American Diabetes Association. ADIPS $=$ Australasian Diabetes in Pregnancy Society. $C D A=$ Canadian Diabetic Association. FPG = fasting plasma glucose. $\mathrm{GCT}=$ glucose challenge test. $\mathrm{HbA}_{\mathrm{lC}}=$ glycated haemoglobin. IFG = impaired fasting glucose. IGT = impaired glucose tolerance. NICE = National Institute for Health and Clinical Excellence. OGTT = oral glucose tolerance test. RACGP $=$ Royal Australian College of General Practitioners. UK $=$ United Kingdom. US = United States. 
testing regimens, recommendations regarding lifestyle interventions to prevent type 2 diabetes progression are absent from the ADIPS guidelines, but the Diabetes Australia/ Royal Australian College of General Practitioners (RACGP) Diabetes management in general practice $2014-2015^{8}$ and Guidelines for preventive activities in general practice (the "red book"; also distributed to GPs in Australia) ${ }^{25}$ outline diabetes management and dietary advice for diagnosed cases in general practice and for diabetes prevention.

Many similarities exist between the diet for GDM and diabetes prevention (ie, focus on low glycaemic index, low saturated fat, high fibre content). However, during a pregnancy complicated by GDM, there is a major focus on tightly controlled blood glucose levels, although appropriate diet quality for pregnancy requirements and gestational weight gain is also paramount. By contrast, diabetes prevention diets have a greater focus on weight reduction. Currently, there is no effort to explain to women who have had GDM the difference in approach.

\section{A missed opportunity?}

Although GPs view follow-up care as their role within the broader context of general health screening and promotion, this is often opportunistic. ${ }^{26}$ Advice from GPs is a powerful motivator for women to adopt lifestyle modification. ${ }^{27}$ However, GPs report not being well versed in guidelines for GDM follow-up care, potentially reflecting the lack of clarity in the literature and their varying knowledge and confidence in provision of lifestyle advice and interventions. ${ }^{28}$ GPs generally give appropriate exercise advice, but can be less clear about dietary or weight loss goals. ${ }^{26}$

These practices are reinforced by systems and process barriers of prioritisation of issues during a consultation, a lack of integration of recall tools and intervention resources in daily workflow, and uncertainty about responsibility for screening, as well as poor communication between secondary and primary care sector and fragmentation of pre- and postnatal care services. ${ }^{28}$

\section{Right information, right people, right time}

Clinical trials have demonstrated that lifestyle modifications with weight loss and moderate exercise can reduce the incidence of type 2 diabetes by up to $58 \%$ for people at high risk, with an impact still evident 8 years from the intervention onset and 4 years after the active intervention ceased. ${ }^{29}$ Real-world implementation in the Australian health care system has achieved $40 \%$ reduction in the risk of progression to diabetes. ${ }^{30}$

Agreement between and willingness to work in partnership with key stakeholders — such as ADIPS, Diabetes Australia, the RACGP and the Royal Australian and New Zealand College of Obstetricians - is required for a collective approach to delivering diabetes prevention to this high-risk population.

However, despite convincing evidence about effective programs in Australia, postnatal support after a pregnancy with GDM is lacking and is without coordination. Interventions using technologies such as telephone, SMS and the internet have been trialled for diabetes care and may be useful in prevention. These must be underpinned by behaviour change theories and address barriers to making changes regarding future risk. ${ }^{23}$ Women have been identified as being receptive to messages several months after birth, which may align with "transition times" (eg, introduction of solids). ${ }^{23}$ Further efforts are urgently needed to develop lifestyle strategies that meet the specific needs of this group of women.

Diabetes Australia's National Gestational Diabetes Register (NGDR), part of the National Diabetes Services Scheme, was launched in 2011 as a free service to women with a Medicare card to help those who have had GDM to manage their health and prevent progression to type 2 diabetes. One function of the NGDR is to send regular reminder letters to women and their GPs regarding diabetes checks (at registration, 12 weeks after birth, and annually thereafter). These reminder letters also include general information for the women and their families to help them continue a healthy lifestyle.

Although the NGDR outlines what testing to undertake, its potential to allow implementation and dissemination of a comprehensive, consolidated set of guidelines is perhaps underused. It could facilitate effective connection of women with a history of GDM with specific, effective, evidence-based lifestyle advice as well as clinical guidance for their GPs.

\section{A call to action: the need for a collaborative approach}

A clear pathway, developed between all stakeholders, with delineated roles and responsibilities to ensure that bestpractice care is delivered along the continuum of antenatal, postnatal, interconception and longer-term care is required. Delivery of coordinated, effective programs is essential for this group of women. Without such clarity, and in the absence of a systems approach to care, we are failing to seize an opportunity to reduce the incidence of type 2 diabetes and promote the wellbeing of these women and their children. After a diagnosis of GDM, women view their GP as the most appropriate source of follow-up care, ${ }^{24}$ so it is imperative that GPs are given the right guidelines and education to advise these women about preventing or delaying progression to type 2 diabetes.

Acknowledgements: We gratefully acknowledge project funding from the Australian Primary Health Care Research Institute, and Fellowship funding from the National Health and Medical Research Council Translating Research into Practice program. We thank Professor Timothy Skinner and Caroline Nicholson who provided advice in the drafting of this article.

Competing interests: No relevant disclosures.

Provenance: Commissioned; externally peer reviewed.

1 Ratner RE, Christophi CA, Metzger BE, et al. Prevention of diabetes in women with a history of gestational diabetes: effects of metformin and lifestyle interventions. J Clin Endocrinol Metab 2008; 93: 4774-4779.

2 Moses RG, Morris GJ, Petocz P, et al. The impact of potential new diagnostic criteria on the prevalence of gestational diabetes mellitus in Australia. Med J Aust 2011; 194: 338-340.

3 Metzger BE. Long-term outcomes in mothers diagnosed with gestational diabetes mellitus and their offspring. Clin Obstet Gynecol 2007; 50: 972-979.

4 Wilkinson SA, Tolcher D. Nutrition and maternal health: what women want and can we provide it? Nutrition \& Dietetics 2010; 67: 18-25. doi: 10.1111/j.1747 $-0080.2010 .01404 . x$.

5 Institute of Medicine. Crossing the quality chasm: a new health system for the 21st century. Washington, DC: National Academy Press, 2001.

6 McElduff A. Shared care: gestational diabetes. Aust Fam Physician 2003; 32 : $113-117$.

7 Nankervis A, Mclntyre HD, Moses R, et al; Australasian Diabetes in Pregnancy Society. ADIPS consensus guidelines for the testing and diagnosis of gestational diabetes mellitus in Australia. Sydney: ADIPS, 
2013. http://www.adips.org/downloads/ADIPSConsensusGuidelinesGDM03.05.13VersionACCEPTEDFINAL.pdf (accessed Apr 2014).

8 Royal Australian College of General Practitioners; Diabetes Australia. Diabetes management in general practice 2014-2015. Sydney: RACGP, 2014. http://www.racgp.org.au/your-practice/guidelines/diabetes (accessed Jun 2014).

9 Endocrinology Expert Group. Therapeutic guidelines: endocrinology. Version 5. Melbourne: Therapeutic Guidelines Limited, 2014.

10 American College of Obstetricians and Gynecologists. Postpartum screening for abnormal glucose tolerance in women who had gestational diabetes mellitus. Obstet Gynecol 2009; 113: 1419-1421.

11 American Diabetes Association. Standards of medical care in diabetes 2013. Diabetes Care 2013; 36 Suppl 1: S11-S66.

12 National Institute for Health and Clinical Excellence. Diabetes in pregnancy: management of diabetes and its complications from pre-conception to the postnatal period. London: NICE, 2008. http://www.nice.org.Uk/CG063 (accessed Jun 2014).

13 Canadian Diabetes Association Clinical Practice Guidelines Expert Committee. Clinical practice guidelines for the prevention and management of diabetes in Canada. Can J Diabetes 2013; 37 Suppl 1: S1-S216.

14 International Association of Diabetes and Pregnancy Study Groups Consensus Panel Writing Group, Hyperglycemia and Adverse Pregnancy Outcome Study Steering Committee. The diagnosis of gestational diabetes mellitus: new paradigms or status quo? J Matern Fetal Neonatal Med 2012; 25: 2564-2569.

15 Sacks DA, Hadden DR, Maresh M, et al. Frequency of gestational diabetes mellitus at collaborating centers based on IADPSG consensus panelrecommended criteria: the Hyperglycemia and Adverse Pregnancy Outcome (HAPO) Study. Diabetes Care 2012; 35: 526-528.

16 McIntyre HD, Oats JJ. Gestational diabetes needs to be managed. Med J Aust 2013; 198: 78-79.

17 Crowther CA, Hiller JE, Moss JR, et al. Effect of treatment of gestational diabetes mellitus on pregnancy outcomes. N Engl J Med 2005; 352: 2477-2486.

18 Landon MB, Spong CY, Thom E, et al. A mulitcentre, randomized trial of treatment for mild gestational diabetes. N Engl J Med 2009; 361: 1339-1348.
19 Reader D, Splett P, Gunderson EP; Diabetes Care and Education Dietetic Practice Group. Impact of gestational diabetes mellitus nutrition practice guidelines implemented by registered dietitians on pregnancy outcomes. J Am Diet Assoc 2006; 106: 1426-1433.

20 McIntyre HD, Oats JJ. Gestational diabetes needs to be managed [letter]. Med J Aust 2013; 198: 595-596.

21 Morrison MK, Collins CE, Lowe JM. Postnatal testing for diabetes in Australian women following gestational diabetes mellitus. Aust N Z J Obstet Gynaecol 2009; 49: 494-498.

22 Sterne VL, Logan T, Palmer MA. Factors affecting attendance at postpartum diabetes screening in women with gestational diabetes mellitus. Practical Diabetes International 2011; 28: 64-68a. doi: 10.1002/pdi.1559.

23 Lie ML, Hayes L, Lewis-Barned NJ, et al. Preventing type 2 diabetes after gestational diabetes: women's experiences and implications for diabetes prevention interventions. Diabet Med 2013; 30: 986-993.

24 Kim C, McEwen LN, Piette JD, et al. Risk perception for diabetes among women with histories of gestational diabetes mellitus. Diabetes Care 2007; 30: 2281-2286.

25 Royal Australian College of General Practitioners. Guidelines for preventive activities in general practice. 8th ed. Melbourne: RACGP, 2012.

26 Ball L, Hughes R, Desbrow B, Leveritt M. Patients' perceptions of nutrition care provided by general practitioners: focus on type 2 diabetes. Fam Pract 2012; 29: 719-725.

27 Stuebe A, Ecker J, Bates DW, et al. Barriers to follow-up for women with a history of gestational diabetes. Am J Perinatol 2010; 27: 705-710.

28 Lindström J, Peltonen M, Eriksson JG, et al. Improved lifestyle and decreased diabetes risk over 13 years: long-term follow-up of the randomised Finnish Diabetes Prevention Study (DPS). Diabetologia 2013; 56: 284-293.

29 Keely E, Clark H, Karovitch A, Graham I. Screening for type 2 diabetes following gestational diabetes: family physician and patient perspectives. Can Fam Physician 2010; 56: 558-563.

30 Dunbar JA, Jayawardena A, Johnson G, et al. Scaling up diabetes prevention in Victoria, Australia: policy development, implementation, and evaluation. Diabetes Care 2014; 37: 934-942. 